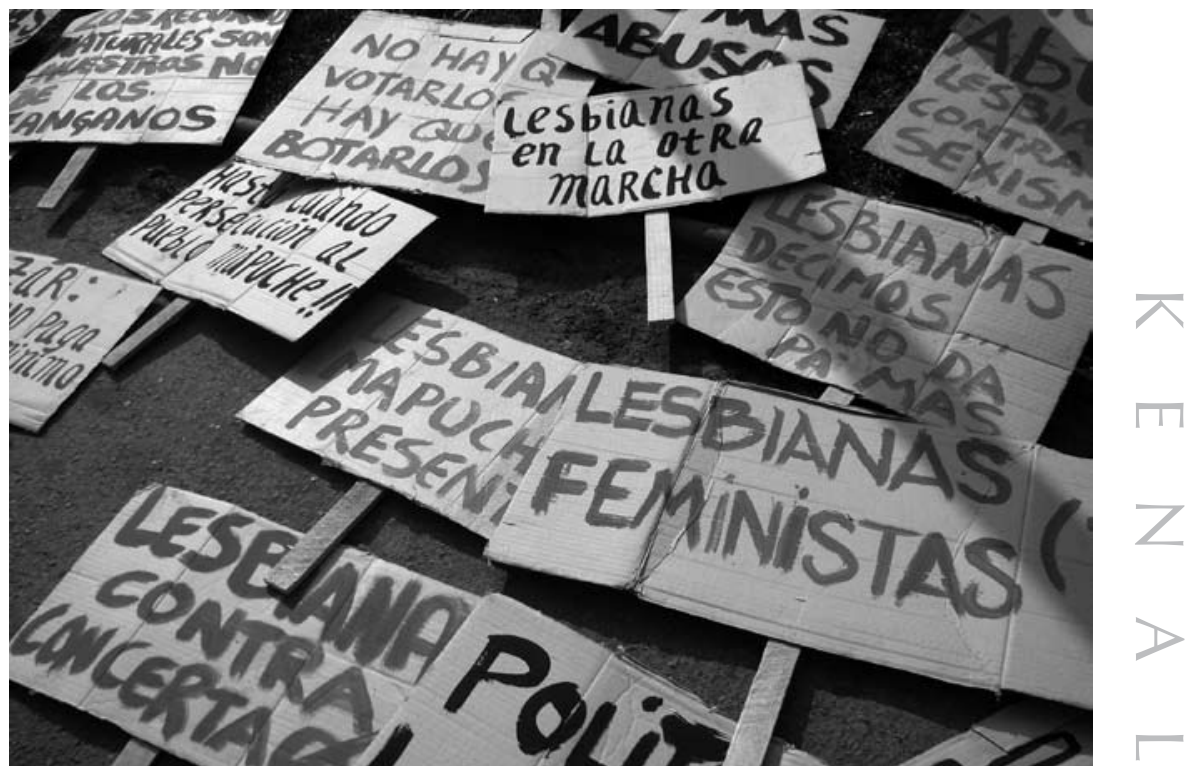

\title{
Antología
}

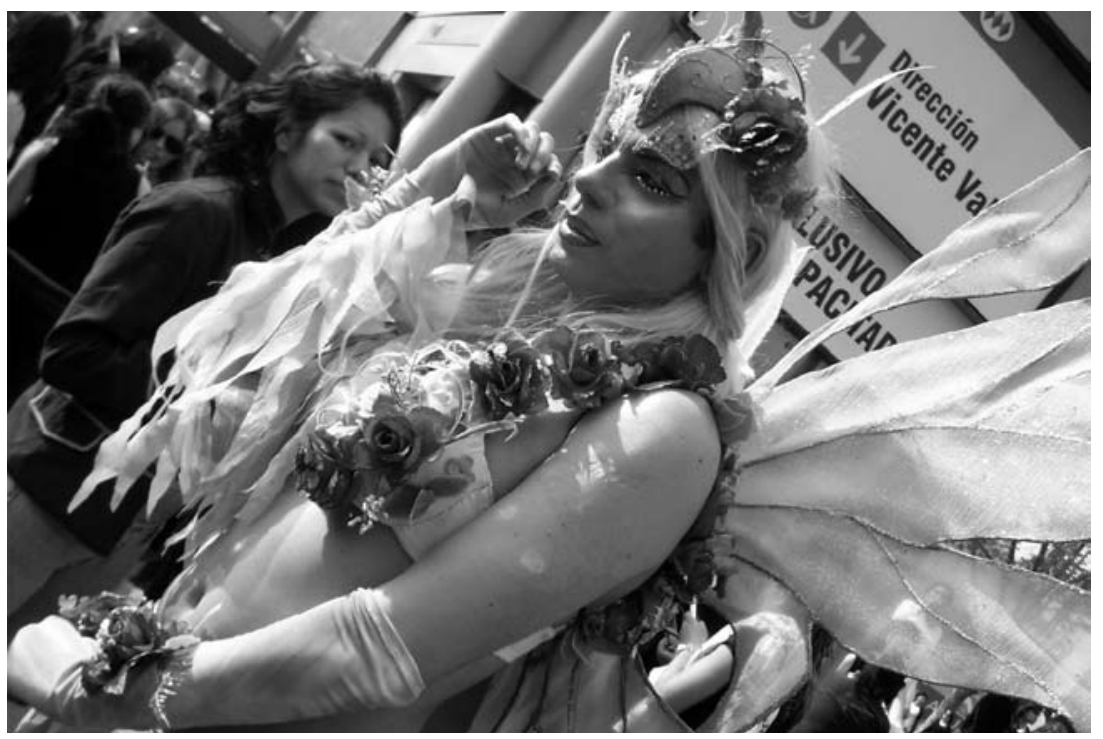

10

11

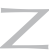

$N$ 


\section{Versos y subversiones. Presencia femenina en la Lira Popular}

\section{Andrea Salazar ${ }^{1}$}

La poesía de cordel o literatura popular impresa fue bautizada como Lira Popular por el pueta ciego Juan Bautista Peralta. La asignación de este nombre habría tenido por objeto parodiar la entonces selecta revista Lira Chilena, destinada a difundir la poesía culta decimonónica. Desde este antecedente podemos comprender que la Lira Popular no era una forma artística representativa de la elite intelectual, sino muy por el contrario. Este tipo de poesía popular impresa se gestó al/ por el calor de las miles de subjetividades en tránsito provenientes del mundo rural que llegaron a poblar la ciudad y que, hacia mediados del siglo XIX, fecha estimada en que se inició la producción de la Lira Popular, contribuyeron a consolidar el centralismo demográfico y socioeconómico de Santiago. Peones, prostitutas, vendedores de motemei, lavanderas, hojalateros, chinganeras, cantores y cantoras, cocheros, aguateros, sujetos que se desplazaban anónimamente entre conventillos, ferias y ranchos, encarnan la mentada ola migratoria provocada por el desarrollo económico de la modernidad. Teniendo en cuenta este panorama, resalta a la vista la mixtura presente en las temáticas de esta poesía que rayan entre la realidad y la ficción; en ella se entrecruzan alusiones a sucesos políticos junto a versos por el angelito, reseñas sobre catástrofes naturales y pronósticos ante el fin del mundo anunciado por profetas, respingados versos por literatura al lado de narraciones sobre el nacimiento de gigantes y monstruos, el descontento por los fusilamientos como pena de muerte y la aparición de Satanás. En fin, los pliegos de la Lira Popular albergan en su interior la heterogeneidad de un discurso producido principalmente por campesinos / as que se acercaron a las ciudades en busca de mejores oportunidades laborales, arrastrando en sus baúles, mitos contados de boca en boca, sus creencias religiosas y la curiosidad por las luces de la modernidad.

Las liras se vendían en lugares populosos como el Mercado 
Central, la Estación de ferrocarriles, plazas y ferias. Se dice que algunos pliegos eran transportados inclusive a regiones. Eran comerciadas por sus propios autores o por suplementeros especialistas en vocear los títulos sensacionalistas y llamativos con que prendían a los lectores; habitualmente los primeros costeaban la impresión de las hojas. Constaban de pliegos de tamaño variable, que aunaban las poesías de un/a solo/a autor/a -quien firmaba al pie de página- y que en su parte superior presentaba ilustraciones o grabados artesanales ad hoc a los asuntos que trataban los versos. La mayoría de estos datos fueron aportados por el filólogo alemán Rodolfo Lenz, quien habiendo llegado a Chile en 1890, se interesó prioritariamente por dos temas: la poesía y cultura popular, la lengua y literatura mapuche. Esto resulta muy interesante si pensamos que un lingüista como Lenz, entre cuyas experticias estaba el dominio del latín, griego, hebreo y otros tantos idiomas, haya elegido como objeto de estudio aquellas materias sobre las cuales el cogollo intelectual chileno jamás se había preocupado. En su publicación fundacional La poesía popular impresa de Santiago de Chile del año 1894, se encarga de ligar esta forma artística con la décima de ocho sílabas o espinela, llamada así en homenaje al poeta cortesano Vicente Espinel. Muy conveniente para la nemotecnia resulta esta forma poética: los/as representantes del mundo logocéntrico leían, declamaban o cantaban en voz alta las liras, acto seguido los analfabetos y las cantoras populares las aprendían de memoria, retornando así al ámbito de la oralidad. Sin embargo la Lira Popular cultivada por los puetas modificó la estructura básica de la espinela con la incorporación de un pie o estrofa de despedida que no seguía la rima anunciada en la cuarteta de inicio, según la cual terminaba cada estrofa siguiente. Dos de las liras antologadas escapan a esta métrica; se trata de la cuarteta "Versos dedicados a una peladora que vive en la calle de la Bandera" y la poesía de tres estrofas "Deberes de los casados a la mujer".

La selección que aquí ofrecemos, tuvo como norte la búsqueda de hojas de versos cuyos contenidos apuntaran a evidenciar la presencia femenina y, en dos casos, las disidencias sexuales. Las mujeres serán actoras y receptoras, protagonistas y personajes de las narraciones líricas. Sin embargo, no podemos dejar de apreciar que la aparición de ellas surge principalmente por tratarse de mujeres "diferentes", sujetos que desbandan la manera 
adecuada de comportamiento impuesto por las construcciones simbólicas ya sea de la obligación heteronormativa, del binomio vida privada/vida pública o de cualquiera de los componentes del sistema sexo-género que rigen la sociedad.

Nos encontraremos entonces con jóvenes que rompen paradigmas y acceden al mundo del trabajo, como es el caso de las conductoras de tranvía que tanto llamaron la atención de los poetas populares. Ellas abandonan la esfera de la vida privada y pasan a engrosar las filas de trabajadores que mantienen en movimiento grandes ciudades como Talca o Concepción.

Por otro lado, veremos picarescas alusiones al cuerpo en " $\mathrm{La}$ pulga intrusa". Creemos que la sensualidad evocada en esta poesía rompe en parte los tabúes en torno al cuerpo como lo prohibido, innombrable, aquello que debe ser conquistado y silenciado; si consideramos que toda referencia al cuerpo queda eliminada del cogito cultural, reafirmamos que los / as autores / as de las liras pertenecían a sectores sociales considerados "incultos", al punto de atreverse a realizar estas impúdicas referencias.

Punto aparte requieren los versos sobre femicidios. Son muchos los títulos que anuncian la muerte de mujeres a manos de hombres: "Horroroso drama. Un joven da muerte a su querida por celos al terminar una cueca", "Espantoso crimen. Una niñita violada y después quemada viva", "Drama salvaje. Por causa de los celos, el marido que le pegó treinta i seis puñaladas a la mujer y después de muerta la degolló". El modelo cultural legitima la discriminación y la violencia contra la mujer arraigándolas en la mentalidad colectiva. Es de suma preocupación reflexionar sobre el nulo avance que ha habido en esta materia. Del mismo modo que en la Lira Popular, incipiente medio de comunicación que coqueteaba con los albores del periodismo y el folletín, los asesinatos de mujeres convocan la atención de los mass media porque "venden". Sin considerar la diferencia de alrededor de ciento cincuenta años, perfectamente podríamos pensar que ese titular corresponde a la portada del diario La Cuarta.

Sin ánimo de seguir adelantando aquello que los/las poetas narran con mucha más gracia, diremos que los pliegos que componen esta antología pertenecen a las tres colecciones de Lira Popular sobre las cuales se tiene antecedentes. Ellas son las colecciones del propio Rodolfo Lenz (Col. Lenz), de Raúl Amunátegui (Col. Am.) y de Alamiro de Ávila (Col. A.A.). Las referencias 
sobre cada una de ellas se desglosa en la información sobre los pliegos originales, disponibles en el Archivo de Literatura Oral y Tradiciones Populares de la Biblioteca Nacional, y la ubicación de ellas en publicaciones. Asimismo, la iconografía que acompaña las poesías corresponde a los grabados populares que ilustraron las liras originales. 


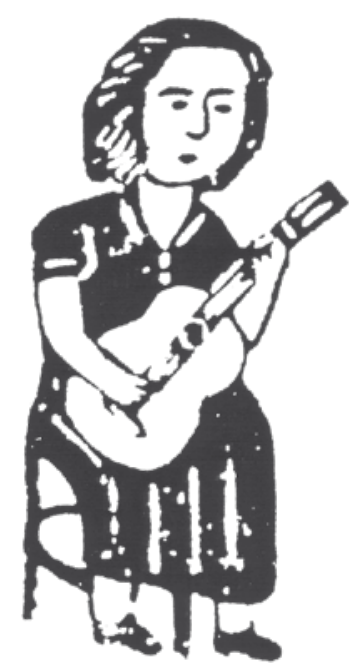

\section{VERSOS DEDICADOS A CINCO CONDUCTORAS TALQUINAS}

Rosa Araneda

Cinco bellas conductoras

De la Empresa talquina,

Por lo sucias i cochinas

Cual de ellas es mas corredora.

La ocho es la Ana Luisa,

Muchacha bien elegante,

De los cocheros amante

Por lo diabla i lo chusquiza.

Su cara llena de risa

La verán a todas horas

Como avecillas canoras

Cantando i salagardeando,

Hácia sus carros charlando

Cinco bellas conductoras.

La quince es la Regalinda

Hermana de la primera;

Tambien sigue la carrera

De la otra que le brinda

Porque a ella se le rinda

El judas, pues, se le inclina

I parece que se empina

Esta mula redomona;

Es pero que vaca bramona

De la Empresa talquina.

La Zoila es número cinco,

De un carácter atractivo,

Mas parece vomitivo
La zamba al pegar un brinco. No crean que me les hinco

A esta comparsa de chinas;

Son una plaga de ruinas,

Créanmelo que es verdad,

Infestan a la ciudad

Por lo sucias i cochinas.

La once es la Rosalía;

Lo que no pueden creer,

Es por mal proceder

Estampa de la herejía;

Esta suja dia a dia

Habla imitando a una lora.

Con mi pluma revisora

Les voi a poner la plancha,

I al sacarlas a la cancha

Cual de ellas es mas corredora.

Al fin, la Juana María,

La seis, chei del inspector,

Conoce bien el lector

Por su lujo i fantasía.

Si acaso él las convia

No deben de ir al trote;

Cuando se les alborote

I les hable del asunto,

Júntense en un mismo punto

I les dan un buen capote.
En pliego:

El cabo del Constitución que se mató por el amor. Col. Am. II, 314, mic. 44.

\section{En libro:}

Navarrete, Micaela, comp. y estudio. Aunque no soy literaria. Rosa Araneda en la poesía popular del siglo XIX. Santiago: Ediciones de la Dirección de Bibliotecas, Archivos y Museos, 1998, 236. 


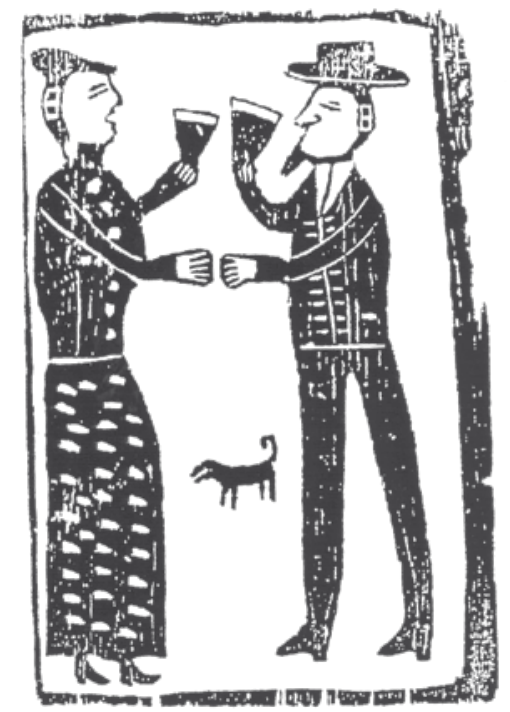

\section{VERSOS DEDICADOS A UNA PELADORA QUE VIVE EN LA CALLE DE LA BANDERA}

Rosa Araneda

En la calle de la Bandera

Hai una chica mugrienta, Lo mismo que perra hambrienta

Ladra, ladra esa ramera.

Hallo mejor que no fuera Tan sucia i tan habladora, Con su lengua corrupta Péla al jénero humano, I con este verso llano Atájate peladora.

De mí dice de contino De que yo paso mintiendo, I ella se lleva lambiendo Platos me dijo un vecino. Ese oficio es mas cochino Yo te lo pruebo aquí ahora, Infame calumniadora, Cara de leon africano I con este verso llano, Atájate peladora.
Dime quien te dió poder Mulata yegua rabona, Que hables de mi persona Fuego humiando sin arder. Tendrás que el palo morder Con hambre de hora en hora, Aquí al són de la tambora Te casco de bien temprano, Con este versito llano, Atájate peladora.

Si siempre te queda gana Yo te las sabré quitar, Hasta que te haga gritar Imitando a una rana Bien te sacudo la lana Con mi mano revisora, Si te tienes por señora No hables tanto que es en vano, I con este verso llano, Atájate peladora.
En pliego:

Crimen en San Felipe. El teniente que asesinó al Sr. Rios en la Alameda. Col. Lenz V, 29, mic. 28.

En libro:

Navarrete, Micaela, comp. y estudio. Aunque no soy literaria. Rosa Araneda en la poesía popular del siglo XIX. Santiago: Ediciones de la Dirección de Bibliotecas, Archivos y Museos, 1998, 238. 


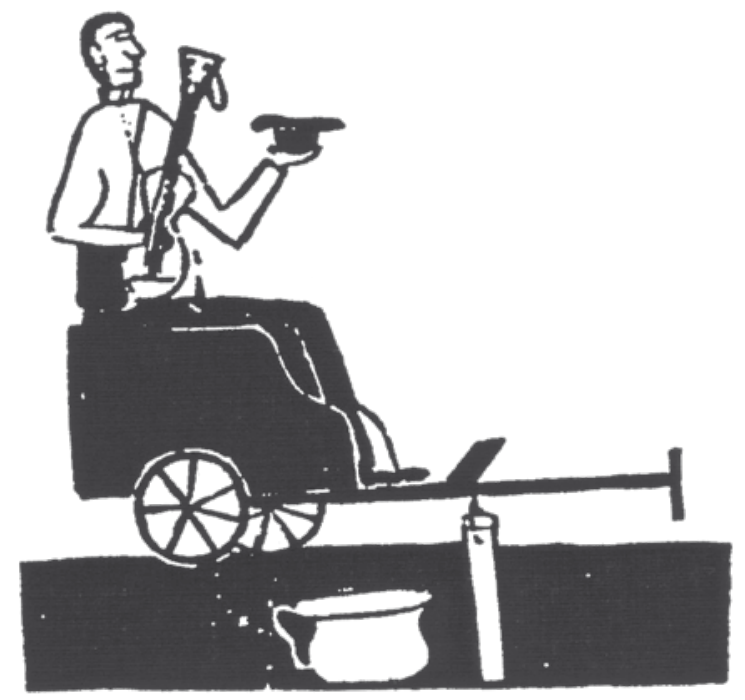

COMPARACIONES ENTRE EL PERRO I LA MUJER

Daniel Meneses

Mas vale querer a un perro

Que no a una ingrata mujer;

El perro es agradecido

Cuando le dan de comer.

Cuando un amante prefieres Amar a una buena moza, Se le pone ella orgullosa Lo desprecia i no lo quiere Solamente cuando muere Viene a conocer el yerro, Sobre esto mismo me aterro Porque me han hecho ofensa Para no pasar vergüenza Mas vale querer a un perro.

Si la tiene regalona De balde yo lo he notado El día menos pensado, Se le pone rezongona Luego busca otra persona Sin mirar el padecer; Opine según mí ver Sumerjido en el dolor Amar a un perro es mejor Que no a una ingrata mujer.
Es necesario tener

A la bella en atención, Siempre a media ración Hasta que aprenda a querer; Darle poco de comer I así el hombre es querido Si ella lo echa al olvido Digo aquí como con arte, Con el amo en cualquier parte El perro es agradecido.

La mujer día por día Si se cuida con amor, Se pone de mal humor Causa de la regalía Pegarle mejor sería Bien de alba al amanecer Si no quiere obedecer Entregarla a Satanás El can obedece más Cuando le dan de comer.

\section{Al fin es mui natural} Decirle a todo amante La mujer es la causante, Que el hombre sea fatal
Ella causa todo mal;

I la reina al ser viviente Claro i verificante

Os digo aquí a todo amado

De que ya está comprobado Que el perro es más obediente.

\section{En pliego:}

Horroroso crimen en Lo Miranda, cuatro niños martirizados, un padre verdugo i un hermano salvaje, Col. Am., I, 63, mic. 10.

\section{En libro:}

Navarrete, Micaela y Daniel Palma, comp. y estudios. Los diablos son los mortales. La obra del poeta popular Daniel Meneses. Santiago: Ediciones de la Dirección de Bibliotecas, Archivos y Museos, 2008, 632. 


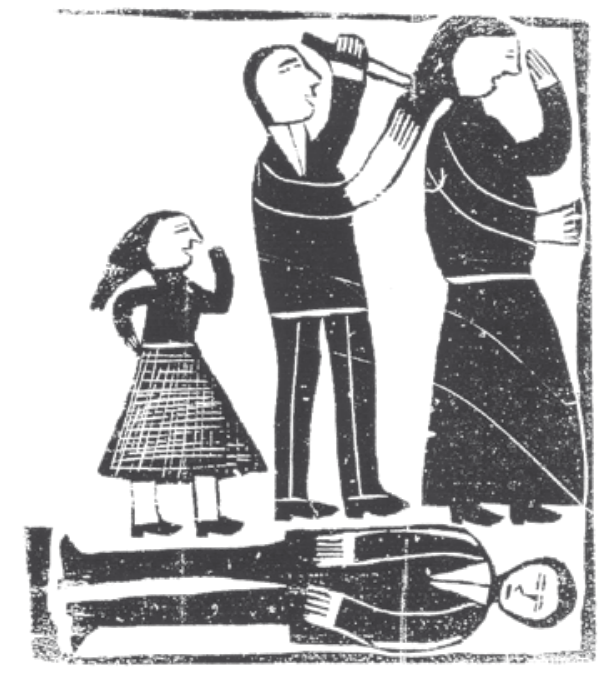

\section{EL MARIDO QUE ULTIMÓ A LA MUJER I AL LACHO PORQUE LOS PILLÓ DURMIENDO JUNTOS}

Rosa Araneda

En la ciudad de la Union

Un asesino gabacho

Mató a la mujer i al lacho

Con justísima razon.

El domingo que pasó

$\mathrm{Al}$ despuntar los albores,

De un improviso, señores,

Esta desgracia ocurrió.

Del modo que principió

Daré yo la esplicación,

Con tristísima emocion

Lectores mios les cuento,

Sucedió el drama sangriento

En la ciudad de la Union.

Llegó el marido celoso

A la casa i los pilló;

Durmiendo los encontró

Con un sueño delicioso.

El crímen mas alevoso

Hizo imitando a un borracho,

I despues a un despacho

Se fué a tomar, doi aviso,

Que es el que estas muertes hizo

Un asesino gabacho.
El hombre tenia idea

Que ella le ponia el gorro,

I como no era mui porro

La ultimó sin dar pelea.

Para que el crímen se vea

Lo hizo en su mismo despacho;

Pero yo aquí se lo tacho,

Aunque le parezca mal;

Con un cortante puñal

Mató a la mujer i al lacho.

En la cama los halló,

Haciendo no sé qué cosa;

Luego la mujer mañosa

Malamente lo trató.

Porque no se le humilló

Ella i le pidió perdon,

Si no como tiburon

Lo recibió de tal suerte,

Por eso él le dió la muerte

Con justísima razon.

Por último al querido,

Sin mirar el hombre en nada, Lo echó de una puñalada
A la mansion del olvido

Lo dejó tan mal herido

Que hoy se encuentra muerto ya, ¡Ai, por Diosito, papá!

Le decia una niñita,

Con susto la pobrecita:

¡No me mate a mi mamá!

En pliego:

El marido que ultimó a la mujer i al lacho porque los pilló durmiendo juntos. Col. Am., II, 333, mic. 47.

\section{En libro:}

Navarrete, Micaela, comp. y estudio. Aunque no soy literaria. Rosa Araneda en la poesía popular del siglo XIX. Santiago: Ediciones de la Dirección de Bibliotecas, Archivos y Museos, 1998, 134. 


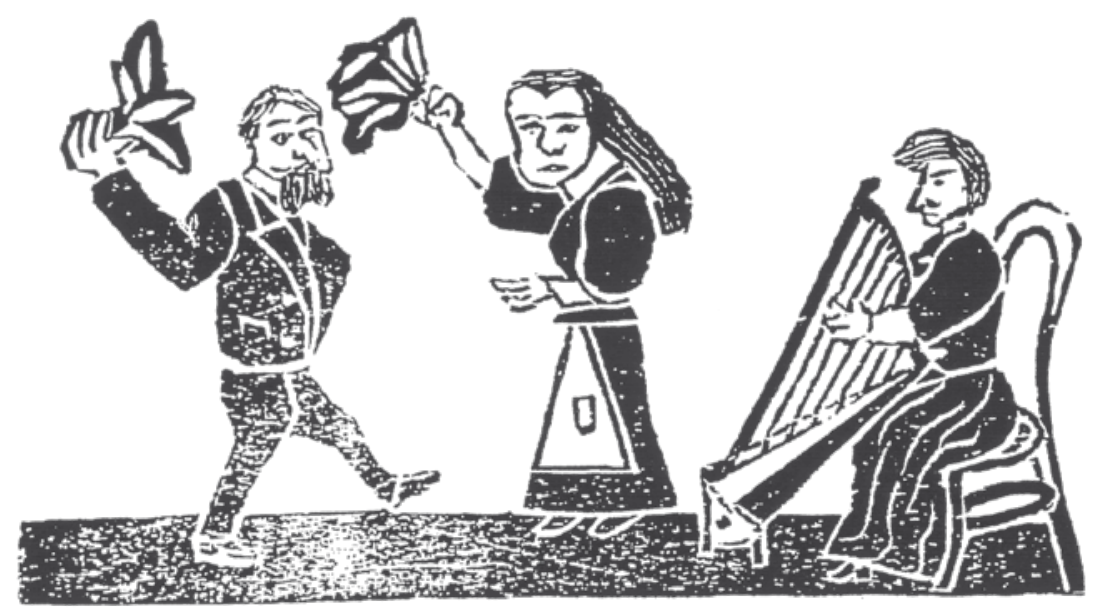

LA PULGA INTRUSA

José Hipólito Cordero Casas

A una niña bonita

Esta pulga le picó

En una parte esquisita

La ronchita le dejó.

Esta pulga de curiosa

Se puso a hacer la escursion

Hasta encontrar posesion

En la parte mas hermosa

En aquel sitio reposa

Clavando su lancetita

Viendo aquella plazuelita

Solo se regocijaba

Poco a poco le picaba

A una niña bonita.

Ya de tanto investigar

Las costas de arriba abajo

En el doblez del refajo

Esta se pudo ocultar

Mas la niña al despertar

Una comezon sintió

Luego la vela encendió

Por pillar esta golosa

A orillas de Mendoza

Esta pulga le picó.
Quedó la dama otra vez

En un poderoso sueño

I la intrusa con empeño

Volvió a picarle despues

Con porfia i rapidez

Siguió la misma betita

Principió aquella maldita

De nuevo a incomodar

Gusto le daba al picar

En una parte esquisita.

Esta golosa porfiaba

Permanecer en la huella

Pero al pronto la doncella

Con ira la correteaba

Tranquila no la dejaba

I en esto se desveló

Después que sueño tomó

Volvió a dañarle con prisa

I a la raíz de la camisa

La ronchita le dejó.

Al fin la pulga dañina

Doble despues la pagó

Cuando la niña la halló

En vuelta en una pretina
Aquí morirás indina

Dijo al darle el apreton

No has tenido compasion

De mí, veleidosa impura,

I sin darle su parte al cura

Desistió sin con confesion.

En pliego:

La invasión de culebras en Carampangue. Inevitable choque de la tierra con el cometa Biela. Col. A.A., $\mathrm{N}^{\mathrm{o}}$ 284.

En libro:

Navarrete, Micaela, selección y prólogo. La lira popular. Poesía popular impresa del siglo XIX. Santiago: Editorial Universitaria, 1999, 18. 


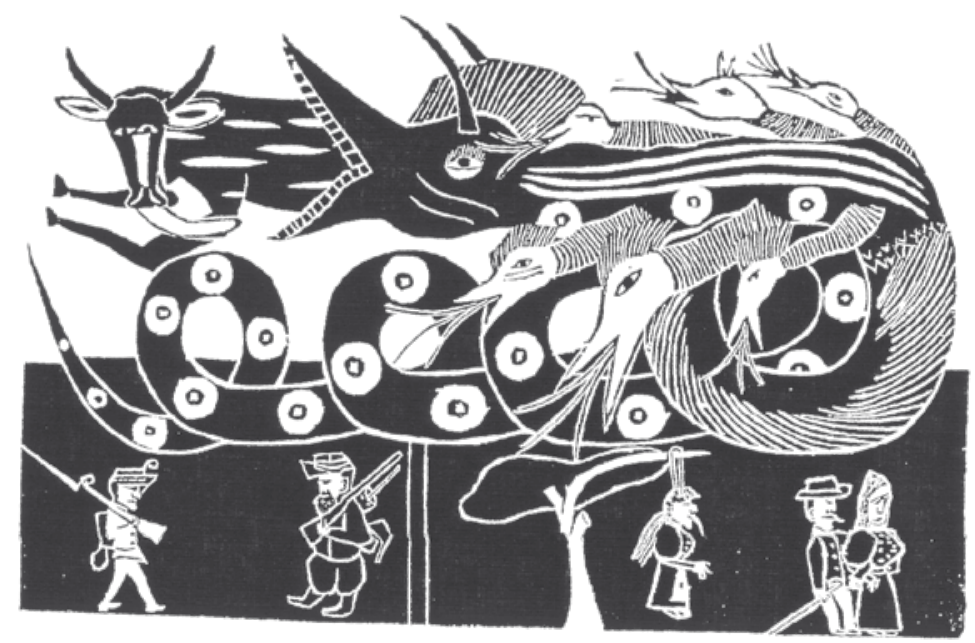

\section{VERSOS HUMANOS UNA REPRENSIÓN A LA MUJER VARIABLE}

Daniel Meneses

Ayer me dijiste que hoy, Hoy me dirás que mañana, Mañana me vas a decir: Ya se me quitó la gana.

No seái variable, mujer, Mira que mucho te afea $Y$ dile a quien te desea Cuándo lo piensas querer; Para nunca más volver De tu lado yo me voy, Bien desengañado estoy, Ver que mi tiempo perdí; Que ibas a darme el sí Ayer me dijiste que hoy.

Dime cuál es tu pensar Que tienes para conmigo, Por la fuerza yo te obligo Para poder descansar; Paso en continuo penar Con una esperanza vana, Hallo larga la semana En la vida del tormento: Si te cobro el juramente, Hoy me dirás que mañana.
Habéis echado al olvido

Mi fino amor verdadero, Siendo que tanto te quiero Cumple con lo prometido; Viéndome de amor herido Más no puedo resistir, Qué te ganas con mentir Si eres falsaria inconstante: Ya tengo otro nuevo amante, Mañana me vas a decir.

\section{Engañosa sin amor}

Te vais con quien te convida, Pretendes pasar tu vida Lo mismo que el picaflor; En nada miras tu honor Por llevarte en la jarana, Bien de alba por la ventana Yo fui pa verte de prisa, Me dijiste con sonrisa: Ya se me quitó la gana.

Por último, la coqueta Nunca ha tenido buen fin: Vuela como volantín Y con nadie se sujeta;
$\mathrm{Ni}$ al casado lo respeta Viendo que es un hombre ajeno;

Si no hay quien le tire el freno La joven sola se mata, Pero que en viéndoles plata A todos les dice: Bueno.

En pliego:

Horrible crímen. El marido da muerte con una pala. Versos humorísticos, quintillas y canciones de puro amor. [1895] Col. Lenz, VII, mic. 39. Col. Am., I, 5, mic 1.

En libro:

Muñoz, Diego, selección. Poesía popular chilena. Santiago: Editorial Quimantú, 1972, 61-62.

Navarrete, Micaela y Daniel Palma, comp. y estudios. Los diablos son los mortales. La obra del poeta popular Daniel Meneses. Santiago: Ediciones de la Dirección de Bibliotecas, Archivos y Museos, 2008, 144. 


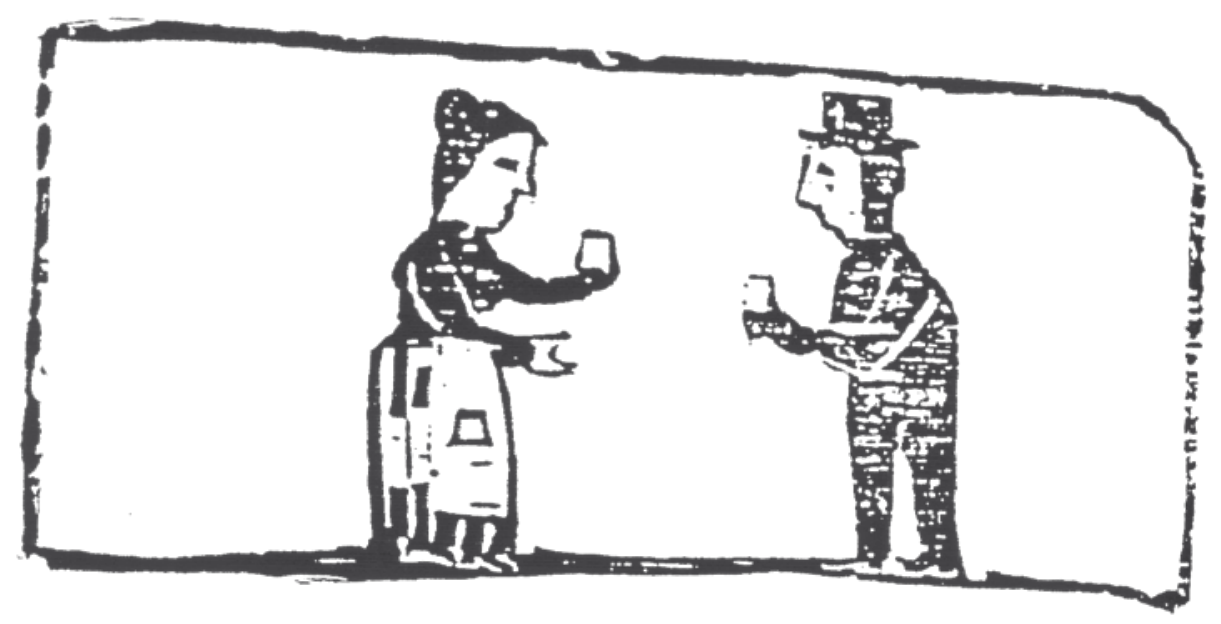

\section{TERRIBLE I TRÁJICO SUCESO. UNA NIÑA CALUMNIADA DIO MUERTE A SU OFENSOR}

Rosa Araneda

Ánjel Petraglia fué

Muerto por una mujer

Porque era un calumniador

Segun mi humilde entender.

Parssans, la jóven Elena, Juró de darle la muerte, I castigarlo bien fuerte Para desechar su pena. Tranquila i mui serena Se encuentra ella les diré, Diciendo ya me vengué; I con la vida ha pagado El que mi honra ha quitado Ánjel Petraglia fué.

La jóven salió temprano En busca de su rival, A hacerle un terrible mal Con impulso soberano. Lo esperó con pecho ufano Con la pistola al creer; Para tiempo no perder, Mas, como ella estaba alerta, El fue, al entrar por la puerta, Muerto por una mujer.
Avisó a la policía

Que preso se lo tomaran,

I como allí se negaran

Fue mas grande su ironía.

Con la mayor sangre fria

Propuso librar su honor,

Armándose de valor

I estando en la oscuridad,

Lo victimó sin piedad

Porque era un calumniador.

Dos cartas el amador

No ménos él le mandó

Al padre cual las leyó

Con sentimiento i dolor.

Caro le costó el amor

Las delicias y el placer;

Cuando quiso atras volver,

Siente el fuego que lo abraza,

I murió en su propia casa

Segun mi humilde entender.

Al fin, por su propia boca Avisó al guardian del punto, I éste, al ver el asunto,

Se creyó que estaba loca.
La sorpresa no fué poca

$\mathrm{Al}$ saber la autoridad

El hecho de esta verdad

Se publicó sin demora,

En ménos de media hora

Se esparció por la ciudad.

En pliego:

Terrible i trájico suceso. Una niña calumniada dió muerte a su ofensor. Col. Am. II, 300, mic. 41.

En libro:

Navarrete, Micaela, comp. y estudio. Aunque no soy literaria. Rosa Araneda en la poesía popular del siglo XIX. Santiago: Ediciones de la Dirección de Bibliotecas, Archivos y Museos, 1998, 141. 


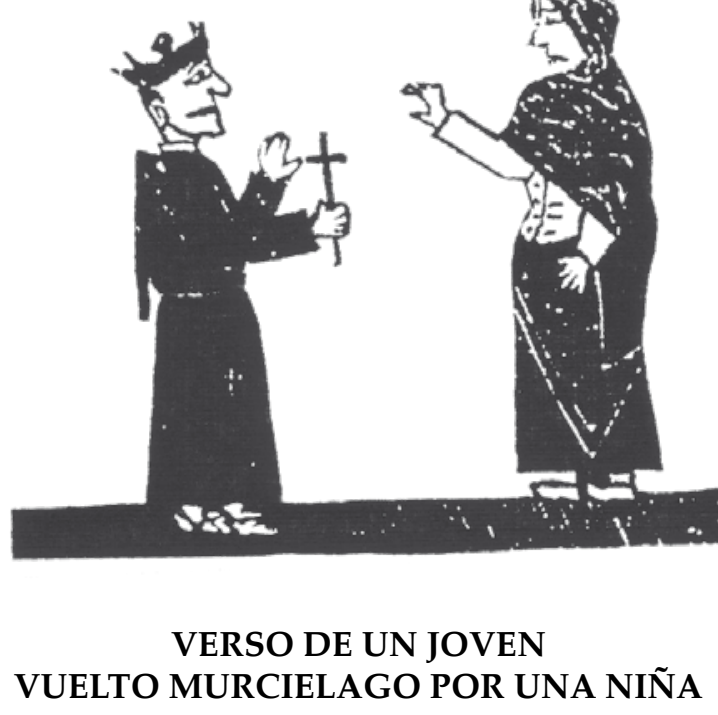

Rosa Araneda

Un jóven se enamoró

De una niña por burlarse

La pobre para vengarse

Murciélago se volvió.

Un marchante pretendia

A una esbelta muchacha

Creyendo que con su facha

Talvez la convenciera

Pero a cuanto él le decia

Ella contestaba nó

Pero su amor lo invitó

A amar aquella deidá

En lo mejor de la edá

Un jóven se enamoró.

Le declaró su pasion

Porque la encontró solita

Se entregó a la muchachita

De todito corazón

Mui pronto i sin dilación

Propuso del atracarse

I principiaron a amarse

Sin mirar ningun respeto

I se templó este sujeto

De una niña por burlarse.
El la habló de casamiento Por ver si algo conseguia Pero ella no le creia A su falso juramento Le contestó con acento Que no queria engañarse Porque para deshonrarse Iria donde la invite Solo a buscar desquite La pobre para vengarse.

La madre de la guainana Era bruja de las fina Por eso la mui indiana Embrujó aquella persona Pues bastante regalona Es la bella bien sé yo El demonio le ayudó De este modo como indico Con el arte diabolico Murciélago lo volvió

Al fin el pobre marchante Que poco no sufrirá Mientras viva no será Acaso lo que era ante
Le pesa haber sido amante De aquella ingrata mujer Porque lo hace padecer Solo por una venganza Pero tiene la esperanza Que otra lo vuelva a su sér.

En pliego:

Un joven muercielago por una niña. Col. Lenz V, 36, mic. 30.

En libro:

Navarrete, Micaela, comp. y estudio. Aunque no soy literaria. Rosa Araneda en la poesía popular del siglo XIX. Santiago: Ediciones de la Dirección de Bibliotecas, Archivos y Museos, 1998, 242. 


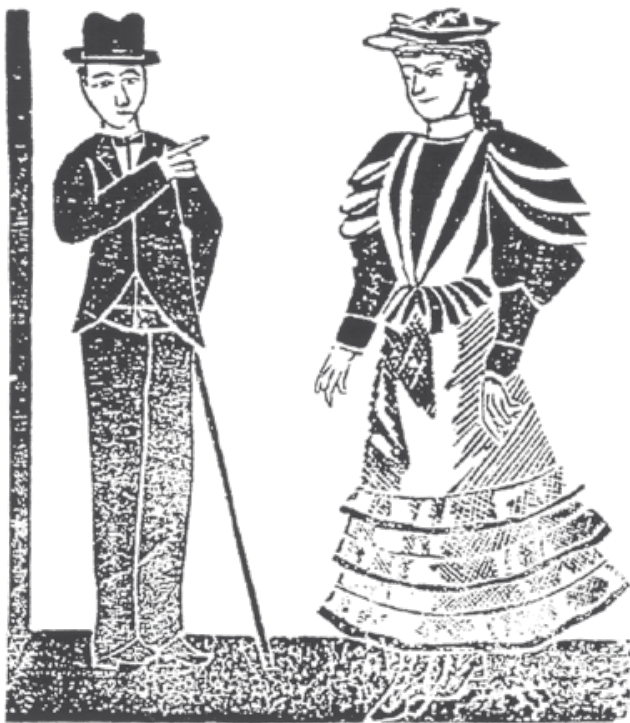

\section{LA NIÑA VESTIDA DE HOMBRE QUE SE CASÓ CON OTRA NIÑA EN ILLAPEL}

\section{José Hipólito Casas Cordero}

En el pueblo de Illapel

Dos mujeres se casaron Siendo mujeres las dos Las bendiciones tomaron.

Lectores con emocion Cuentan mis sentidos finos De dos sexos femeninos Que han causado admiracion. Se ha visto en esta Nacion Aquel error mas infiel Hoy lo detalla el papel Del suceso que pasó Por esto que se palpó En el pueblo de Illapel.

Una se crió vestida De galan i de buen paño I a su tiempo hizo el engaño Petardiando a su querida, A la novia parecia Que era un varon cuando hablaron

Luego que se enamoraron Tuvieron gusto i honores, Por dar fin a sus amores Dos mujeres se casaron.
De este cuadro de rareza

Pido que nadie se asombre, I la que se vistió de hombre Cometió esta gran torpeza La poca delicadeza

La ha hecho engañar a Dios. Como futre i de relos

Por conyugarse se apura

Sin saber las casó el cura

Siendo mujeres las dos.

Su inocencia la pago

La novia i contrajo el mal, La noche del conyugal

Sola se desengaño;

Tal mujer es como yo

Decia i bien le observaron

Los que al templo acompañaron

Estaban en la conquista

Con un engaño a la vista

Las bendiciones tomaron.

Al fin es mui admirable

Este raro matrimonio

I en oficio del demonio
Fué el consorte incomparable,

Ocultar no será dable

Porque falto a los deberes

Por ignorancia estos seres

Esta falta cometian

Del amor que se tenian

Se casaron dos mujeres.

En pliego:

La niña vestida de hombre i que se casó con otra niña en Illapel. Guerra entre Chile i la Arjentina i los versos de Balmaceda. Col. A.A. N 269.

\section{En libro:}

Navarrete, Micaela, selección y prólogo. La lira popular. Poesía popular impresa del siglo XIX. Santiago: Editorial Universitaria, 1999, 18. 


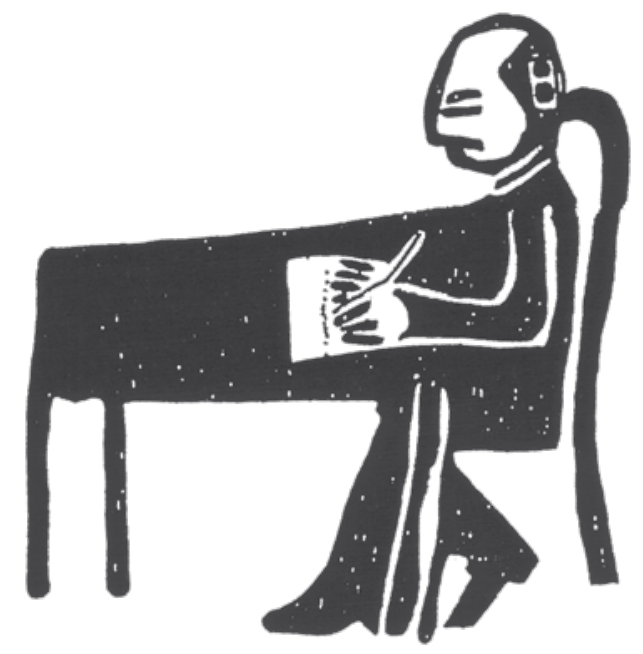

EL MARICON VESTIDO DE MUJER

José Hipólito Casas Cordero

Un ejemplo nunca visto

En Quillota sucedió;

De quince años un varón,

Con otro hombre se casó.

Observaciones al caso:

Que es muy raro y distinguido

Que uno de mujer vestido

Tomó estado con un huaso;

Lo hizo consorte a su plazo

El novio llamado Sixto

Que por no ser muy peristo

Jamás violó sus amores,

Diré que ha sido, señores,

Un ejemplo nunca visto.

Este, de niña tunante

Llegó al pueblo con presteza

Como la mejor princesa

Y de cara interesante;

Viéndola tan elegante,

Della un galán se prendó

Y como se petardó

La recibió por esposa;

La escena tan horrorosa

En Quillota sucedió.
Por el nombre de Enriqueta

Pasaba ese desatento;

La noche del casamiento

Fue pillado este coqueta;

El novio buscó la veta

Cuando pasó la función

Y le salió maricón

La mujer que pretendía;

Ya me la pegó, decía,

De quince años un varón.

La madre, según se opina, Al hijo lo malcrió,

Desde chico lo vistió

Con ropitas femeninas;

Diai viene la doble ruina

Que este infame recibió:

El marido lo llevó

A pedir perdón a Roma,

Porque imitando a Sodoma

Con otro hombre se casó.

Al fin de Roma llegó

Con bendiciones plenarias,

Pero a las Islas Canarias

El Papa lo desterró;
Por diez años le salió

Aquella dura condena, Sólo preso y con cadenas Aquel perdón le fue dable; La vida del miserable

Me da compasión y pena.

En pliego:

¡COMPRAME LECTOR! Col. A.A. $\mathrm{N}^{\circ} 248$.

En libro:

Muñoz, Diego, selección. Poesía popular chilena. Santiago: Editorial Quimantú, 1972, 29-30. 


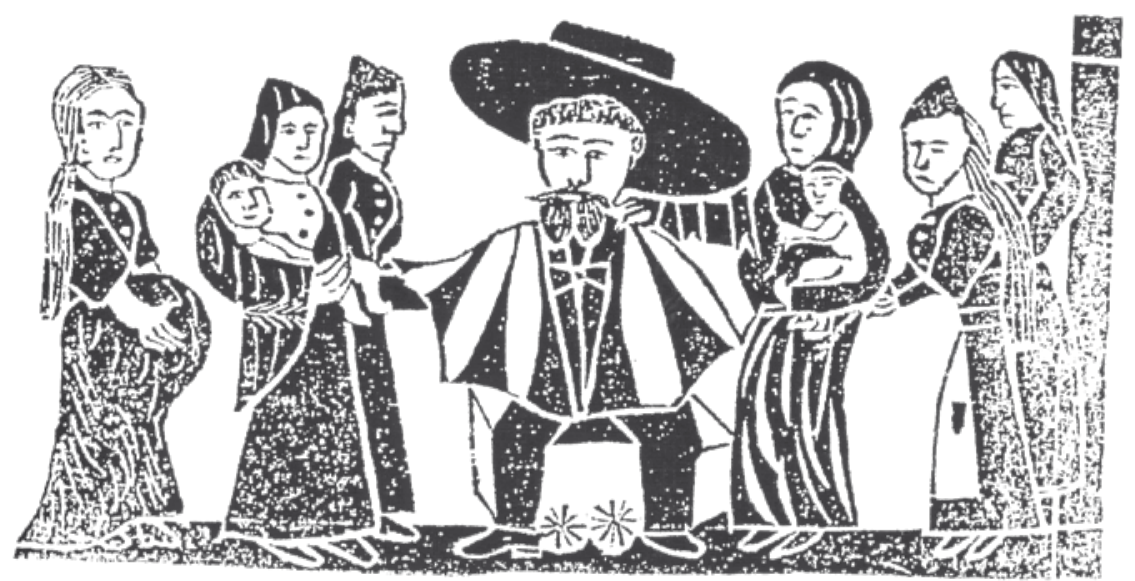

\section{LA HIJA QUE ARRASTRÓ A LA MADRE DEL PELO PORQUE NO LA DEJABA CASARSE}

José Hipólito Cordero

Un suceso mui estraño

En Cauquenes sucedió: Una hija regalona

A la madre le pegó.

Lectores, voi a narrar Un caso estraordinario Que se publicó en el diario I que sirve de ejemplar. Me dan ganas de llorar, I es verdad i no les engaño: Esta atrevida un gran daño A la madre le causó, I por cometer se vió Un suceso mui estraño.

He sabido que por celos Esta fatal inhumana A su triste madre anciana Vino i la tomó del pelo. Pronto el castigo del cielo El Hacedor le mandó:

Un brazo se le secó Por hacer tal desacato. Esto que yo les relato, En Cauquenes sucedió.
Se llama la Juana Rosa

Esta pobre libertina,

I quiso ser asesina

Esta ingrata veleidosa.

Como sierpe venenosa,

Como un ser digno se encona.

La justicia no le abona

I le aplicó su condena;

Así pagará su pena

Una hija regalona.

Ésta tenía un amante, I a su madre la juzgaba Que con el mismo trataba Se figuró la ignorante. Con un furioso semblante Media cuadra la arrastró.

Al cautiverio cayó

Por este feroz arrojo,

I así con ira i enojo

A la madre le pegó.

Señores, mui admirable Ha sido este raro ejemplo: A la salida del templo Se avanzó esta miserable;
Ahí se hizo responsable

Del espantoso perjuicio;

Esta maldad fue con vicio, Oigan los que están naciendo, I por lo que se está viendo Serán las señas del juicio.

En pliego:

El caballero pegado en el caballo en Curepto. La hija que arrastró del pelo a la madre por no dejarla casarse. Col. A.A. N 266.

La chilota que dió a luz un niño con tres cabezas, en el Parral. Col. A.A. $\mathrm{N}^{\mathrm{o}} 267$.

En libro:

Navarrete, Micaela, selección y prólogo. La lira popular. Poesía popular impresa del siglo XIX. Santiago: Editorial Universitaria, 1999, 19. 


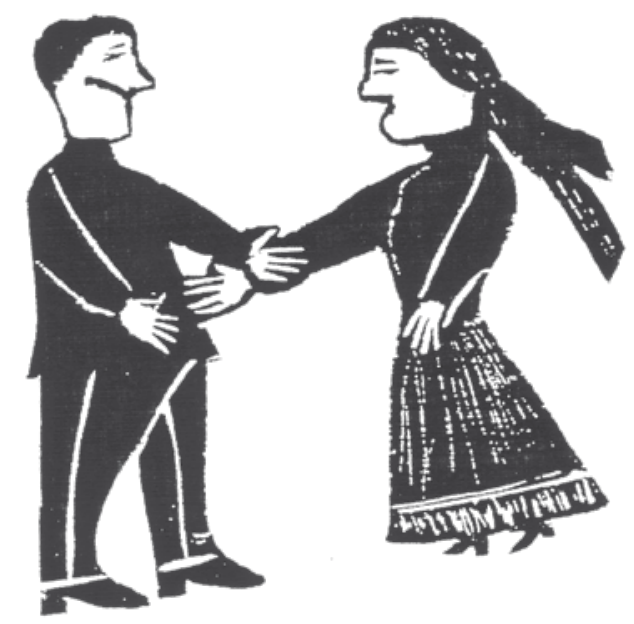

\section{DEBERES DE LOS CASADOS A LA MUJER}

Juan Bautista Peralta

Oid niñas si has querido Ahora matrimoniarte Como tú debes portarte Con ese esposo querido. Por primero a tu marido Gusto le tienes que dar I todo en primer lugar Le debes a tiempo hacer Así te sabrá querer I gozaras en tu hogar.
Los afeites dejaras Tambien las chinchoserias I aun las coqueterias Que son leseras demas. Dia a dia mantendras El hogar limpio i hermoso, Albo el lecho del reposo I todo bien arreglado, I así te habras conquistado Mas el amor de tu esposo.
Tu tampoco no has de ir A donde la vecinita Que le gusta la cuequita Porque esto te hará sufrir, En pieza en pieza, es decir No debes andar por nada I deja la bufonada Con hombres sin faltar, Si no deseas pasar Por tu marido pateada.

\author{
En pliego: \\ La Lira Popular No 72 . Un médico \\ milagroso. Col. A.A. No 198. \\ En libro: \\ Navarrete, Micaela y Tomás Cor- \\ nejo, comp. y estudio. Por historia \\ y travesura. La lira popular del poeta \\ Juan Bautista Peralta. Santiago: \\ Ediciones de la Dirección de Biblio- \\ tecas, Archivos y Museos, 2006, 60.
}

\section{Nota}

1 Estudiante de Magíster en Estudios de Género y Cultura de la Universidad de Chile. 